\title{
Distance travelled to tertiary pediatric care impacts care-seeking behavior and hospital outcome in Vietnam
}

\author{
David A Rollins', Timothy T Xu', Viet Hoang ${ }^{2}$, Khang Tuan Hoang ${ }^{2}$, Sarah S Kang ${ }^{3}$, Toan Ngoc Pham², Duy Ngoc Le², \\ Yves Ouellette ${ }^{4}$ \\ ${ }^{1}$ Mayo Clinic Alix School of Medicine, Rochester, Minnesota, USA, 2 Department of Emergency Medicine, Vietnam National Children's Hospital, Hà Nôi, \\ Vietnam, ${ }^{3}$ Department of Nursing, Mayo Clinic, Rochester, Minnesota, USA, ${ }^{4}$ Department of Pediatric and Adolescent Medicine, Division of Pediatric \\ Critical Care Medicine, Mayo Clinic, Rochester, Minnesota, USA \\ Keywords: pediatrics, critical care, vietnam, care seeking \\ https://doi.org/10.29392/001c.12102
}

\section{Journal of Global Health Reports}

Vol. 4, 2020

\section{Background}

The absence of appropriate and timely critical care in resource-limited countries like Vietnam contributes to poor outcomes and excessive mortality in the acutely ill, pediatric population. Often, tertiary care is limited to major urban centers and patients from remote locations face lengthy travel. How these distances impact care-seeking behavior of the patients' caregiver, patient acuity on admission, and hospitalization outcome in critically ill children remains unknown.

\section{Methods}

We assessed 471 pediatric patients admitted to intensive care units (ICUs) from the emergency department in a pediatric referral center in Hanoi that serves northern Vietnam. Demographic information from caregivers and medical information was collected by trained staff on site and from the medical record. Patient outcome was followed for sixty days in the ICUs. We analyzed associations between patient admission acuity and outcome to socio-geographic and-demographic data using bivariate logistic regression and log-rank analyses.

\section{Results}

The median child's age in our study was 1.8 months, with the majority under 1 year (83.3\%). On admission to the ICU, $40.5 \%$ of patients required life-saving treatment. Within sixty days of admission, $73.3 \%$ of patients were discharged, $21.8 \%$ experienced extended admission and 3.08\% expired in the ICU. Patient and caretaker's distance from home residence to Vietnam National Children's Hospital (VNCH) greater than 60 kilometers was significantly associated with a more severe patient acuity on ICU admission (Odds Ratio, OR=2.01, 95\% Confidence Limit, $\mathrm{CL}=1.33,3.06$ ), an extended admission or expiration in the ICU $(\mathrm{OR}=1.94,95 \% \mathrm{CL}=1.15,3.20)$, a lower family income $(\mathrm{OR}=3.74,95 \% \mathrm{CL}=2.46,5.64)$, lack of caregiver college education $(\mathrm{OR}=3.73,95 \% \mathrm{CL}=2.34$, 6.05), and greater referrals and days delayed seeking care.

\section{Conclusions}

These findings highlight numerous barriers facing acutely ill children and their caretakers, who must travel long distances to reach appropriate critical care at a tertiary referral hospital. Research into current protocols, skills, and staffing at lower facilities and public health education in these regions is needed to determine the best avenues for improvement of critical care services beyond tertiary centers.

Critical illness in resource-limited countries (RLCs) remains a crucial determinant of all-cause mortality and health outcomes. ${ }^{1}$ The lack of skilled and available emergent and critical care leads to an unacceptably high number of potentially preventable deaths, especially in acutely ill pediatric patients with curable illnesses. ${ }^{2,3}$ In particular, access to tertiary care centers is important for the sickest patients; however, this care is typically limited to central urban areas and more widely available primary and secondary facilities lack the necessary resources to treat the severely ill. ${ }^{4,5}$

Our knowledge on emergent and critical care access in RLCs remains rudimentary. Known factors that result in more severe patient presentations upon admission at a ter- 
tiary care center include low to no medical accessibility, poor recognition of illness, and care in an under-skilled intensive care unit (ICU) $3,6,7$; however, linkages between these factors and patient severity as well as outcome data remain obfuscated. Indeed, a major barrier to quality critical care in RLCs has been the scarcity of epidemiologic data - including patient demographics, understanding of basic medical infrastructure, and outcome data. ${ }^{6,8}$

The effect of geographic distance on access to emergent and higher level care in RLCs has been proposed as an important determinant of patient severity and outcome. ${ }^{9}$ Seeking care at higher-level facilities may involve long distances travelled, further exacerbated by referrals, and may impact the decision to seek care and the severity of patient presentation and outcome. For example, distance to care has been positively associated with maternal and newborn mortality. ${ }^{10}$ Even in resource-abundant countries, distance travelled to emergent care is associated with worse outcome and may impact the decision to seek or complete medical care. ${ }^{11,12}$ Importantly, the greatest association between poor outcome and distance travelled was seen in patients with respiratory conditions 11 - which represents the majority of acutely ill patients in RLCs. ${ }^{13}$ As such, distance travelled is critical to evaluate in RLCs, given the current gap of knowledge on how distance affects care-seeking behavior and outcomes.

A simplistic application of critical care principles in resource-abundant countries, where the cost of care is exorbitant for any one individual, to RLCs is not sufficient and may even be harmful to RLCs 6,14 ; therefore, context-specific analyses within existing emergent and critical care systems in RLCs is warranted to better understand avenues for improvement. However, before improvements in the emergent and critical care system in a RLC can be proposed, the system and its population need to be well-understood. For our study, we focused on Vietnam, a RLC where sharp divides in access to emergent medical care and child mortality persist among socioeconomic classes, age groups, and ethnic backgrounds. ${ }^{15-17}$

In Vietnam, access to care is hierarchical and centralized. Tertiary pediatric care is available in three major cities: Hanoi, Da Nang and Ho Chi Minh. This availability affects patients from remote areas - comprised of mostly lower socioeconomic classes - who face lengthy travel in addition to a cumbersome referral process if they seek care. ${ }^{18}$ Patients often enter the medical system at low- and mid-level facilities due to proximity as well as Vietnam's "gatekeeper referral system" - where care is initially sought at lower levels to prevent overcrowding at high-level hospitals - although emergent care may be sought anywhere. ${ }^{19}$ Importantly, all referrals enter the Emergency Department (ED) before admission to an ICU. Conditions referred to higher level care include infectious diseases, prematurity complications, and respiratory distress. ${ }^{5}$ It is unclear whether Vietnam's referral systems contribute to negative health outcomes or increase access to care by preventing overcrowding.

While Vietnam has reduced child mortality and improved access to pediatric care through nationwide efforts and insurance programs $15,19-25$, the under 5 years old and pediatric ICU mortality rates remain high compared to those rates in resource abundant countries. ${ }^{3,23}$ While past stud- ies have identified vulnerable Vietnamese pediatric patient populations, geographic locations and exacerbating factors contributing to these populations' severe conditions and health outcomes have not been not evaluated. Improvement of children's health in these vulnerable populations warrants examination of the severity of illness when care is sought, referral pattern, and distance traveled to seek care. A focus on how high-level, emergent pediatric care is accessed will help to understand how the current systems function, identify at-risk populations, and ultimately aid in potential interventions or improvements to serve Vietnamese and other RLCs' pediatric populations.

\section{METHODS}

This study was a single center prospective observational study conducted at Vietnam National Children's Hospital (VNCH) in Hanoi, Vietnam, the largest tertiary referral center in Northern Vietnam. Any patient under 18 years of age who was examined in the emergency department, then admitted to an intensive care unit was eligible. For ethical reasons, we excluded patients who died or were imminently dying on ED admission prior to transfer to intensive care as well as their caregivers. This study was conducted during a 5-month period from July 2018 to December 2018. We enrolled 471 patients, 15 of whom were excluded for missing medical admission data.

\section{SURVEY}

Interviewers were trained in informed consent, study processes, and interviewing techniques. Informed consent was received from the accompanying parent or caregiver. Surveys were completed by either a self-administered by a written form or orally administered by a trained interviewer. The survey included questions regarding socioeconomic demographics, care seeking behaviors, numbers of lower level facilities visited, referrals from lower level facilities, mode of transportation, insurance, and travel costs.

\section{ADMISSION AND OUTCOME}

When seen in the emergency department, patient acuity was assigned an Emergency Severity Index (ESI) score in guidance with the ESI v4 Algorithm, a validated tool for assessing patient status in pediatric critical care ${ }^{26}$, independently by two trained ED staff (nurse or doctor) or pediatrics resident physician. ESI score ranged from 1 (requiring immediate life-saving treatment; e.g. compromised airway, unresponsive, or hemodynamic instability requiring emergent pharmacy), 2 (high-risk situation, unstable vitals), 3 (need for multiple interventions; e.g. imaging studies, intravenous fluid, labs), 4 (one intervention needed), to 5 (no interventions needed). Patients' past medical history, outcome of admission, and disposition after discharge were ascertained from the medical record. Outcomes were recorded as regular admission (<60 days), extended admission (>60 days), or expiration in the ICU, and were followed up to sixty days following admission. Outcome data was collected on 383 patients. 


\section{DATA MEASURES}

Variables were dummy coded categorically except for the following numerical variables: age, family members, length of stay, delay in care-seeking, time to closest medical facility, number of facilities visited before $\mathrm{VNCH}$, and transport time to VNCH.

For logistic regression analysis, the main dependent variables (outcomes) assigned were either an ESI=1 (vs ESI $>1$ ), an outcome of extended admission/expiration in the ICU (vs. discharge within 60 days), an answer "Yes" to a variable impacting the decision to seek care (vs. "No"), or a distance greater than $60 \mathrm{~km}$ to $\mathrm{VNCH}$ (vs $<60 \mathrm{~km}$ ). Independent variables (risk factors) were placed in binary categories. Bivariate analysis was completed using the BaptistaPike method to calculate an odds ratio with a 95\% confidence interval and a two-tailed Fisher's exact test to calculate a specific $P$ value.

Our numerical data of days delayed to care or to $\mathrm{VNCH}$ was found to be significantly nonparametric by multiple normality tests (D’Agostino \& Pearson, Shapiro-Wilk, Kolmogorov-Smirnov); we therefore employed log-rank analyses in our comparisons between risk factors. For most analysis, we divided the risk factor into binary categorizations and tested for significance using Mann-Whitney tests and approximate P values. When distance to $\mathrm{VNCH}$ was divided into multiple groups, we assessed for significant differences using one way ordinary ANOVA with Dunnett's corrections for multiple comparisons.

All data analysis was performed on GraphPad Prism 8.0 Software (GraphPad Software Inc, San Diego, CA, USA).

\section{ETHICS}

Approval was obtained from the Institutional Review Board (IRB) at Mayo Clinic in Rochester, Minnesota, USA and Vietnam National Hospital of Pediatrics in Hanoi, Vietnam.

\section{RESULTS}

\section{DEMOGRAPHIC AND ADMISSION DATA}

Our sample contained 456 pediatric patients from provinces in northern Vietnam admitted to an ICU from the VNCH ED (Fig 1, Supplementary Table 1). Demographic data are reported in Table 1. Patients sampled had a median age of 1.8 months, with $83.3 \%$ under 12 months old, and were predominantly Kinh, or Vietnamese ethnic majority (91.4\%), residing in a rural location (64.3\%).

On admission, infectious disease was the most common diagnosis (64.3\%), of which pneumonia and encephalitis prevailed (Table S2 in the Online Supplementary Document). Diagnoses were not mutually exclusive and cardiovascular and prematurity diagnoses were also prevalent. Consistent with the age range and admission diagnoses of our sample, admission to the medical ICU was the highest followed by the neonatal ICU (Table 2). Before ICU admission, patient acuity was scored with the Emergency Severity Index (ESI) V4 algorithm, most patients presented with an ESI=1 (40.5\%), requiring life-saving interventions, or an ESI=2 (48.5\%), requiring multiple emergent interventions. 390 patients were followed in the ICU and outcome data, in-

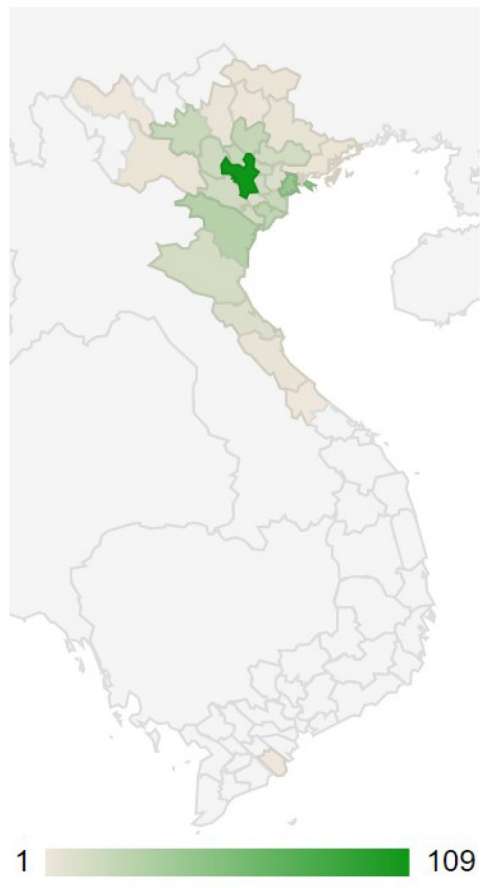

Figure 1. Patient regional distribution.

Number of patients per regional province for tertiary care in Hanoi, Vietnam.

cluding length of stay, was collected.

As VNCH is a major tertiary referral center and patients may have sought care elsewhere, we assessed distance to care and referrals (Table 3). Most patients were within 10 $\mathrm{km}$ to the closest medical facility from their residence (88.9\%); however, in contrast, the most patients were further than $60 \mathrm{~km}$ to $\mathrm{VNCH}(66.1 \%)$. We next analyzed if distance to $\mathrm{VNCH}$ related to the duration of travel patients and their families underwent, and found longer distances took greater travel time (Supplementary Figure 1). If VNCH was not the first facility visited, then the median number of care centers visited was one (57.5\%). The time between the first facility visited and $\mathrm{VNCH}$ admission was widely distributed, with most patients being sent to VNCH within 24 hours (54.3\%).

\section{CARETAKER SURVEY DATA}

The impact of distance and insurance status on care-seeking behavior was analyzed (Table 4). Most patients were covered under government or public health insurance (89.1\%). 33.1\% of caregivers responded the presence of health care coverage impacted their decision to seek medical care for their child. In regards to distance, $20.9 \%$ and $34.9 \%$ of caretakers answered the proximity to the closest medical facility or to VNCH, respectively, impacted the decision to seek care. Ambulance was the main mode of transport to VNCH (73.7\%); however, only in $40.6 \%$ of cases were transportation costs covered by insurance. Importantly, $94.2 \%$ of parents were missing work unpaid to be at VNCH. Caretaker delay to care, the time between recognition of the child's acute illness and the pursuit of care outside the home, had a median of 0 days, with an average of 1.68 days. 
Table 1. Demographic data $(\mathrm{N}=456)$

\begin{tabular}{|c|c|}
\hline Variable & $\mathrm{N}(\%) \pm \mathrm{SD}$ \\
\hline \multicolumn{2}{|l|}{ Sex: } \\
\hline Female & $197(43.2)$ \\
\hline Male & $257(56.3)$ \\
\hline Other & $2(.4)$ \\
\hline \multicolumn{2}{|l|}{ Age: } \\
\hline Mean (Months) & $11.64 \pm 28.8$ \\
\hline Median (Months) & 1.8 \\
\hline$<1$ Month & $181(39.7)$ \\
\hline 1-12 Months & $199(43.6)$ \\
\hline 12+ Months & $76(16.7)$ \\
\hline \multicolumn{2}{|l|}{ Ethnicity } \\
\hline Kinh & $417(91.4)$ \\
\hline H'mong & $6(1.3)$ \\
\hline Mướng & $4(.9)$ \\
\hline Tày & $7(1.53)$ \\
\hline Other & $22(4.8)$ \\
\hline \multicolumn{2}{|l|}{ Family members: } \\
\hline Mean & $4.8 \pm 1.3$ \\
\hline Median & 5 \\
\hline 2-4 members & $222(48.7)$ \\
\hline 5-6 members & $198(43.4)$ \\
\hline 7+ members & $36(7.9)$ \\
\hline \multicolumn{2}{|c|}{ Parent's highest education: } \\
\hline Primary & $9(2.02)$ \\
\hline Lower secondary & $91(20.4)$ \\
\hline Upper secondary & $146(32.7)$ \\
\hline Technical/vocational & $47(10.5)$ \\
\hline College/university & $153(34.3)$ \\
\hline \multicolumn{2}{|c|}{ Family income per person per million VND: } \\
\hline$<1$ & $29(6.39)$ \\
\hline $1-1.3$ & $89(19.6)$ \\
\hline $1.3-2$ & $30(6.61)$ \\
\hline$>2$ & $289(63.7)$ \\
\hline Other & $17(3.7)$ \\
\hline
\end{tabular}

SD - standard deviation, VND - Vietnamese Dong

\section{ACUITY ON ADMISSION RELATIONSHIPS}

Multivariate analysis was performed to examine factors that increased the odds of an admission with the highest acuity ESI score of 1 (Figure 2). The following demographic variables were associated with an ESI=1: age under one month, female sex, family size $>4$ members or $>7$ members, parental lack of college education, and family income under 2 million VND per family member (Figure 2, Panel A). Importantly, insured patients were less likely to present with an $\mathrm{ESI}=1$ on admission.

Given the diversity in distances traveled, we examined the relationship of distance to medical facilities to acuity on admission (Fig 2, panel B). Distances to the closest med- ical facility greater than $10 \mathrm{~km}$ or $30 \mathrm{~km}$ were not associated with a higher acuity on arrival; however, distances to $\mathrm{VNCH}$ greater than $60 \mathrm{~km}$ were significantly associated with increased acuity on admission. Patients who arrived via ambulance to VNCH had a more severe acuity on arrival as well. Additionally, we examined the duration of travel to $\mathrm{VNCH}$ and found patients whose travel went over $60 \mathrm{mins}$ were more likely to have a severe acuity on admission (Figure S2 in the Online Supplementary Document).Patient admission acuity was also related to care-seeking behavior (Figure 2, Panel C); patients who experienced at least 1 day delay to care or to $\mathrm{VNCH}$ had a higher acuity on arrival. Additionally, patients who were referred at least once, and 
Table 2. Admission and Outcome $(\mathrm{N}=456)$

\begin{tabular}{|c|c|}
\hline Emergency Severity Index & $N(\%) \pm S D$ \\
\hline ESI 1 & $185(40.5)$ \\
\hline ESI 2 & $221(48.5)$ \\
\hline ESI 3 & $36(7.89)$ \\
\hline ESI 4 & $13(2.85)$ \\
\hline ESI 5 & $1(.22)$ \\
\hline \multicolumn{2}{|l|}{ Intensive Care Unit: } \\
\hline Medical & $195(46.2)$ \\
\hline Neonatal & $133(31.5)$ \\
\hline Surgical & $52(12.3)$ \\
\hline Cardiac & $42(9.95)$ \\
\hline \multicolumn{2}{|l|}{ Outcome: } \\
\hline Discharged & $286(73.3)$ \\
\hline Extended Admission & $85(21.8)$ \\
\hline Expired & $12(3.08)$ \\
\hline Other & $7(1.79)$ \\
\hline \multicolumn{2}{|c|}{ Length of stay (discharged only): } \\
\hline Median & 15 \\
\hline Mean & $19.81 \pm 17.44$ \\
\hline 1-6days & $63(22.0)$ \\
\hline 7-14days & 106(37.1) \\
\hline 15-29days & $87(30.4)$ \\
\hline $30+$ days & $30(10.4)$ \\
\hline
\end{tabular}

SD -standard deviation, ESI - emergency severity index

A.

B.

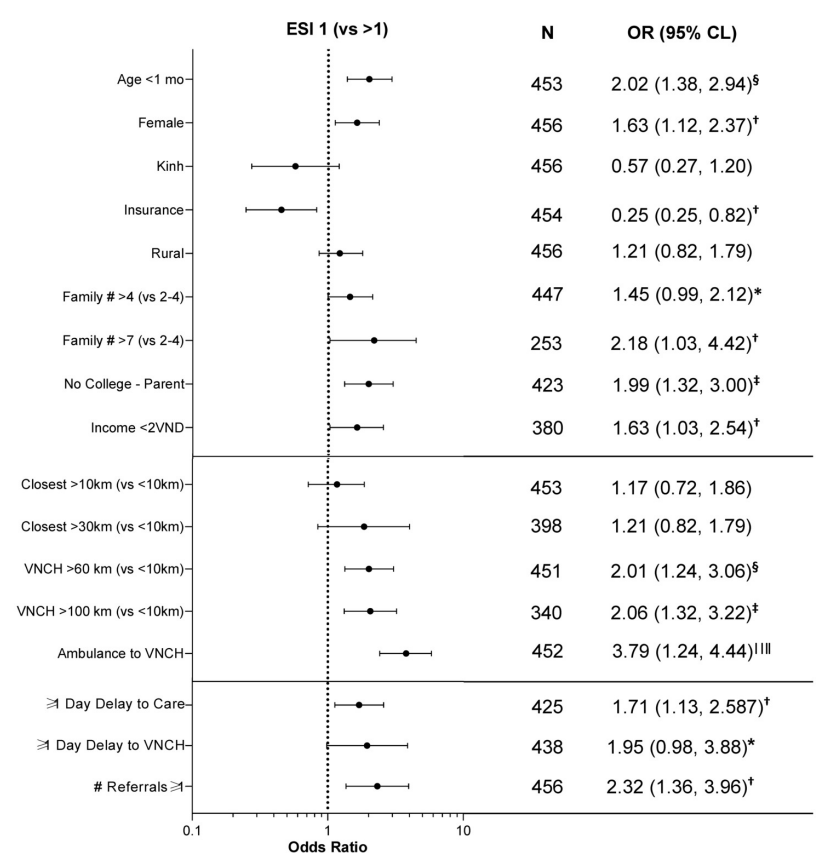

Figure 2. Odds ratios for admission acuity.

$\mathrm{N}=$ number of patients, $\mathrm{OR}=$ odds ratio, $95 \% \mathrm{CL}=95 \%$ confidence limit. ${ }^{*} \mathrm{P}<0.10,+\mathrm{P}<.05, \neq \mathrm{P}<.01, \S \mathrm{P}<.001,\|\| \| \mathrm{P}<0.0001$ 
Table 3. Distance to Care $(\mathrm{N}=456)$

\begin{tabular}{|c|c|}
\hline Variable & $N(\%) \pm S D$ \\
\hline \multicolumn{2}{|c|}{ Distance to closest facility: } \\
\hline $0-10 \mathrm{~km}$ & $364(88.9)$ \\
\hline $11-30 \mathrm{~km}$ & $57(12.7)$ \\
\hline $31-60 \mathrm{~km}$ & $10(2.2)$ \\
\hline $61-100 \mathrm{~km}$ & $10(2.2)$ \\
\hline $101+k m$ & $9(2)$ \\
\hline \multicolumn{2}{|c|}{ Number of facilities visited before $\mathrm{VNCH}$} \\
\hline Mean & $1.09 \pm 0.68$ \\
\hline Median & 1 \\
\hline $\mathrm{VNCH}$ is first & $80(17.6)$ \\
\hline 1 & $261(57.5)$ \\
\hline $2+$ & $113(24.9)$ \\
\hline \multicolumn{2}{|c|}{ Duration from $1^{\text {st }}$ facility to $\mathrm{VNCH}$ : } \\
\hline 0-4hours & $121(32.4)$ \\
\hline 4-24hours & $82(21.9)$ \\
\hline 1-2days & $41(11)$ \\
\hline $2+$ days & $130(34.8)$ \\
\hline \multicolumn{2}{|c|}{ Distance to VNCH: } \\
\hline $0-10 \mathrm{~km}$ & $37(8.2)$ \\
\hline $11-30 \mathrm{~km}$ & $50(11.1)$ \\
\hline $31-60 \mathrm{~km}$ & $65(14.4)$ \\
\hline 61-100km & $112(24.9)$ \\
\hline 101-150km & $93(20.7)$ \\
\hline $151-250 \mathrm{~km}$ & $50(11.1)$ \\
\hline $251+\mathrm{km}$ & $42(9.4)$ \\
\hline
\end{tabular}

SD - standard deviation

thus transferred hospitals at least once, presented with a higher acuity on arrival.

\section{OUTCOME DATA IN THE ICU}

Bivariate analysis was expanded to analyze factors affecting outcome data with odds ratios reported as the odds of an outcome of an extended stay or expiration in the ICU vs. an ICU discharge (Figure 3). We first compared admission acuity with outcome data as the ESI is a widely used tool with well-known construct validity in both adult and pediatric populations. ${ }^{26,27}$ Consistent with a more severe admission acuity, patients with an ESI=1 on admission were more likely to have a worse outcome (Figure 3, Panel A); however, the only demographic data associated with a more severe outcome were parental lack of college education and family income under 2 million Vietnamese Dong (VND) per family member (Figure 3, Panel B). Regarding travel, more severe outcomes were associated with a further distance from home residence to both the closest medical facility and to VNCH (Figure 3, Panel C). Consistent with admission acuity, patients who rode in ambulance to $\mathrm{VNCH}$, experienced at least 1 day delay to any care or to $\mathrm{VNCH}$, and who were referred at least once were more likely to have a more severe outcome (Figure 3, Panels C-D).

\section{DETERMINANTS OF CARE-SEEKING:}

Given the significant association between days delayed to care or VNCH and admission acuity and outcomes, we sought to analyze the factors affecting days delayed careseeking (Figure 4). Intriguingly, increased days delayed care-seeking were associated only with an increased distance to VNCH over $60 \mathrm{~km}$ (Fig 4, panel A); however, when days delayed to VNCH (=days delayed to care + time between first facility and $\mathrm{VNCH}$ ) was calculated, it was positively associated with a greater distance to VNCH and an income lower than 2 million VND per family member (Fig 4, panel B). To understand the range of days delayed to $\mathrm{VNCH}$, histograms for patients fewer than $60 \mathrm{~km}$ and over $60 \mathrm{~km}$ to VNCH were plotted (Fig 4, panel C). Strikingly, the patients within $60 \mathrm{~km}$ to $\mathrm{VNCH}$ were within 16 days from onset of illness to $\mathrm{VNCH}$ admission whereas patients over $60 \mathrm{~km}$ exhibited a right-shift with days delayed to VNCH up to 110 .

We next asked parents about factors that influenced their decisions to seek care and found (Fig 5, panel A): a distance greater than $10 \mathrm{~km}$ to the closest medical facility was more likely to affect the parent's decision to seek care at that fa- 
Table 4. Determinants of care-seeking behavior

\begin{tabular}{|c|c|}
\hline Variable & $\mathrm{N}(\%) \pm \mathrm{SD}$ \\
\hline \multicolumn{2}{|l|}{ Insurance type: } \\
\hline Government/Public & $401(89.1)$ \\
\hline Private & $3(0.67)$ \\
\hline None/Unknown & $46(10.2)$ \\
\hline \multicolumn{2}{|c|}{ Did insurance impact the decision to seek care? } \\
\hline No & $301(66.9)$ \\
\hline Yes & $149(33.1)$ \\
\hline \multicolumn{2}{|c|}{ Did distance to the closest facility impact the decision to seek care? } \\
\hline No & $356(79.1)$ \\
\hline Yes & $94(20.9)$ \\
\hline \multicolumn{2}{|c|}{ Did distance to VNCH impact the decision to seek care?: } \\
\hline No & $293(65.3)$ \\
\hline Yes & $156(34.7)$ \\
\hline \multicolumn{2}{|c|}{ Transport means to $\mathrm{VNCH}$ : } \\
\hline Ambulance & $331(73.7)$ \\
\hline Car/motorbike/public & $118(26.3)$ \\
\hline \multicolumn{2}{|c|}{ Who covered costs to $\mathrm{VNCH}$ ?: } \\
\hline Insurance & $183(40.6)$ \\
\hline Self-paid & $250(55.4)$ \\
\hline Charity & $18(4)$ \\
\hline \multicolumn{2}{|l|}{ Missing work unpaid: } \\
\hline No & $26(5.8)$ \\
\hline Yes & $420(94.2)$ \\
\hline \multicolumn{2}{|c|}{ Delay from illness onset to care-seeking: } \\
\hline Mean delay (days) & $1.68 \pm 7.87$ \\
\hline Median delay (days) & 0 \\
\hline 0 days & $298(67.8)$ \\
\hline 1-2days & $86(19.5)$ \\
\hline $3+$ days & $56(12.7)$ \\
\hline
\end{tabular}

SD - standard deviation, VNCH - Vietnam National Children’s Hospital

cility, a distance greater than $60 \mathrm{~km}$ to $\mathrm{VNCH}$ was more likely to affect the parent's decision to seek care at $\mathrm{VNCH}$, and patient insurance coverage was more likely to affect the parent's decision to seek medical care. A visualization of these impacts on the decision to seek care is shown as percentages per group in Supplementary Figure 3.

As distance to $\mathrm{VNCH}$ greater than $60 \mathrm{~km}$ was associated with impacting the decision to seek care in addition to multiple metrics (outcome, days delayed), we sought to further analyze this population. We found it was associated with caregiver income less than 2 million VND per family member and lack of college education, as well as a greater number of patient referrals (Fig 5, panel B). These data are graphed in Figure 6 and show the near linear relationship between lack of college education and decreased household income to greater distances from VNCH. In addition, we found patient referrals of 1 or greater than 1 are associated with an increased number of days delayed to VNCH.

\section{DISCUSSION}

\section{THE ROLE OF DISTANCE TO CARE}

Our study focuses on emergent cases requiring critical care in northern Vietnam and highlights the effect of distance travelled to a tertiary care center on patient admission and outcome. Importantly, a greater distance to $\mathrm{VNCH}$ was associated with a greater number of days delayed to care and to admission at $\mathrm{VNCH}$ - which were independent predictors of a severe admission acuity and outcome. Indeed, the caretaker's decision to seek tertiary care was more likely to be impacted the further the patient was from VNCH - in particular, those children over $150 \mathrm{~km}$ were most delayed. The cost of seeking care likely delays care-seeking as those further away incurred more expenses at the cost of greater time away from work unpaid and personal travel costs to VNCH as over $50 \%$ of caretaker's self-paid expenses to VNCH. Additionally, patient households in provinces further away from $\mathrm{VNCH}$ are more likely to be in lower income 


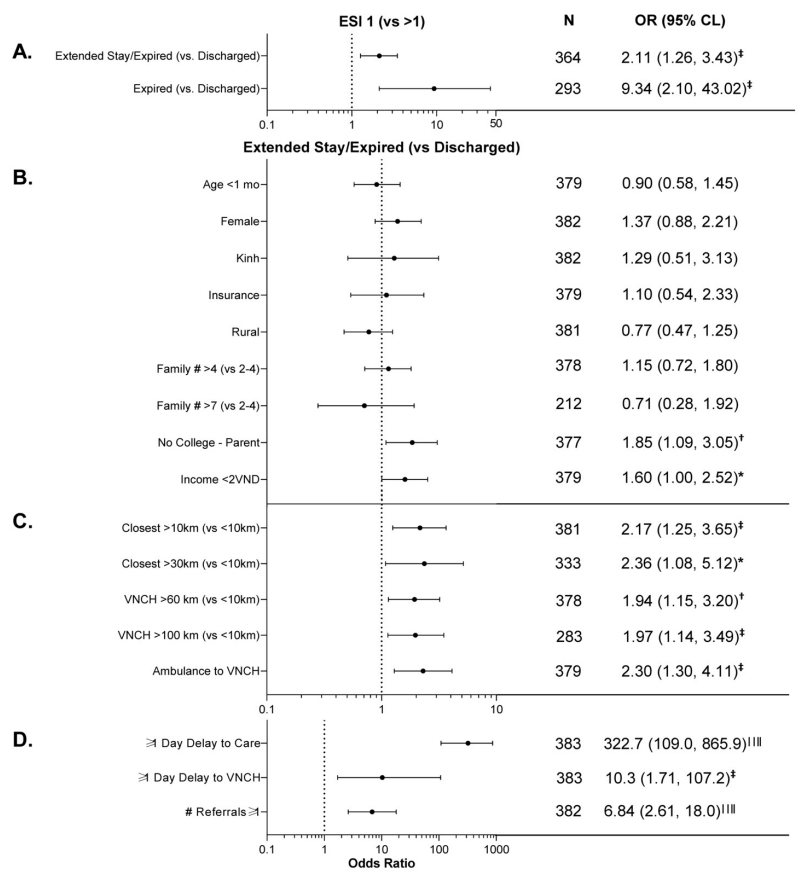

Figure 3. Odds ratios for outcome data.

$\mathrm{N}=$ number of patients, $\mathrm{OR}=$ odds ratio, $95 \% \mathrm{CL}=95 \%$ confidence limit. ${ }^{*} \mathrm{P}<0.10, \mathrm{tP}<.05, \neq \mathrm{P}<.01, \S \mathrm{P}<.001,\|\mid\| \mathrm{P}<0.0001$

brackets, which may constrain caretaker's decisions as we found that a lower income was associated with delaying care-seeking.

It is important to note that many variables (mode of transport, traffic congestion, availability of transport) likely affect the decision to seek care and the journey to tertiary care. In our study, we focused on distance to care, which was related to the duration of travel, because we believe it is a crucially important determinant in care-seeking behavior and health outcomes.

\section{FACTORS IN HEALTH OUTCOMES}

The nature of the referral process and transfers compounds patient acuity and outcome. Our data indicate that any referrals led to worse acuities and outcomes - potentially from care received within the lower and middle level facilities, which lack the standardized protocols, training, and staff to adequately deal with critically ill patients. 5,6,8 Another risk factor is the transportation process itself. Resources in an ambulance are often insufficient and severely sick patients, especially those in respiratory and neurological distress as in our patient population, fare worse with increasing travel. 28,29

The discrepancies in health acuity and outcomes we observed in lower income and distanced patients may partly be explained by the fact $30 \%$ of insured patients pay out-ofpocket to bypass the referral process and seek higher-level care directly. ${ }^{15}$ Additionally, recognition of initial illness can contribute to this aforementioned gap - as poor caretakers are less likely to have higher education and recognize early warning signs to seek care. ${ }^{30-34}$ Consistently, in our study, we observed worse health acuity and outcomes for children whose caretakers did not receive a college educa- tion or were disproportionately located in provinces further from $\mathrm{VNCH}$.

These findings on income and education on patient acuity are in line with a previous study in $\mathrm{VNCH}$ that examined all patients entering the $\mathrm{ED}^{7}$; however, there are important distinctions - our study focuses on patients requiring critical care only and also gathers outcome data to sixty days. More longitudinal outcome data in particular is important given its paucity in LRC research and critical care studies. As most of the patients in our study were severely ill, requiring life-saving treatment often, we felt it was important to follow the outcomes to adequately identify discrepancies between groups.

\section{FUTURE DIRECTIONS}

Ensuing research needs to take into account the at-risk, critically ill patient populations in need of skilled tertiary care at the primary and secondary centers as well as in remote communities. It is possible that children capable of the journey to $\mathrm{VNCH}$ are privileged in contrast to those children unable to make the journey and we are missing those groups who are most at risk. Additionally, a further expansion of our project to other skilled pediatric tertiary care centers in Vietnam or in other LRCs in Southeast Asia would greatly benefit the strength of our findings and the utility of our research for the global health field.

Given that facility distance impacts utilization of care and child mortality in resource-limited environments 35 , resources and expertise should be divided strategically to maximize the health of the pediatric populations. In Vietnam, this allocation could involve standardizing care protocols amongst primary and secondary facilities further than $150 \mathrm{~km}$ from tertiary care centers for prevalent conditions 
A.
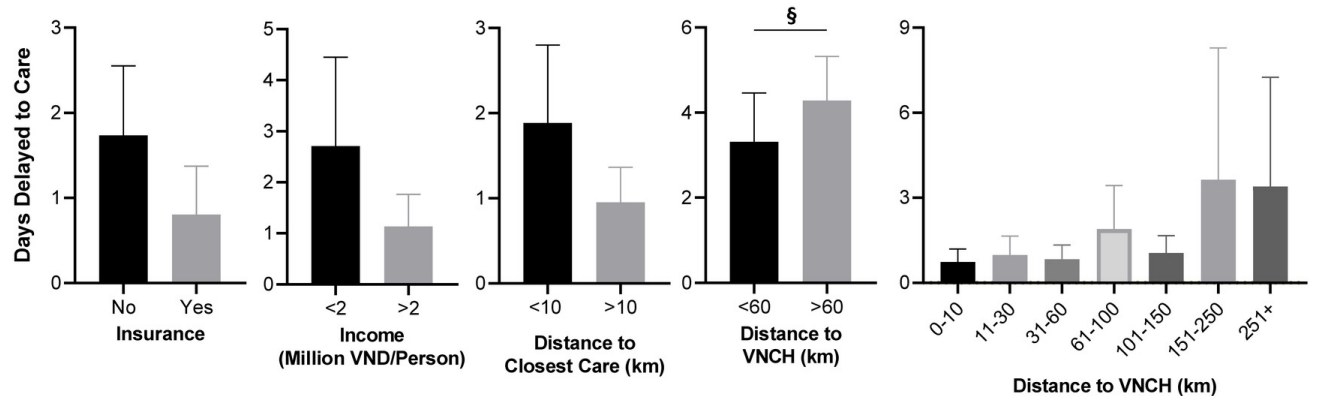

B.

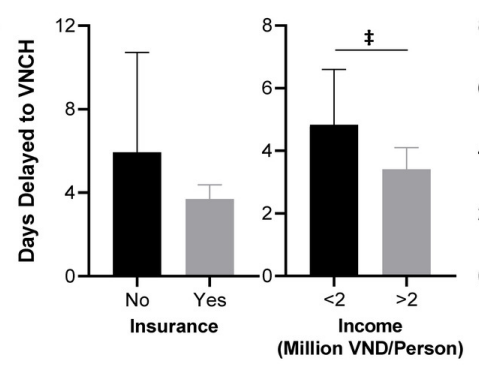

C.

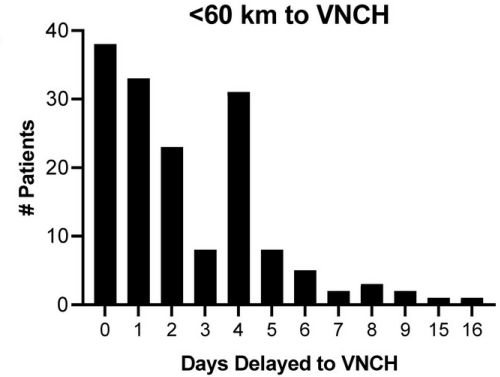

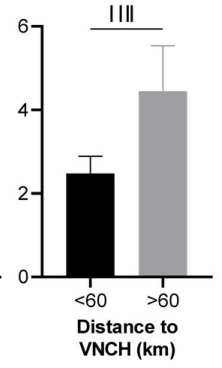

$>60 \mathrm{~km}$ to $\mathrm{VNCH}$

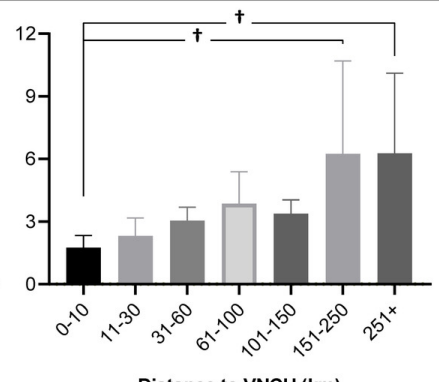

Distance to $\mathrm{VNCH}(\mathrm{km})$

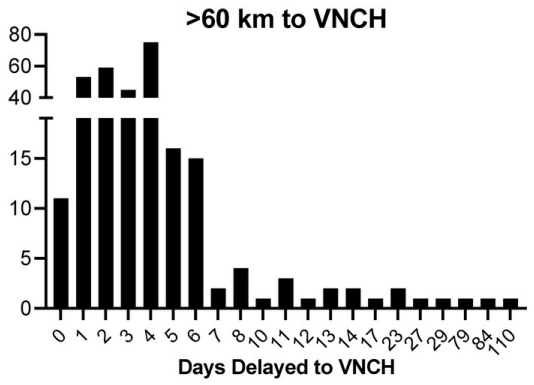

Figure 4. Factors affecting care-seeking.

Panel A. Mean days delayed to care.or to VNCH (Panel B were plotted with 95\% confidence interval error bars for distinct categories. Panel C. Histograms plotted for days delayed to VNCH in patients $<60 \mathrm{~km}$ and $>60 \mathrm{~km}$ to VNCH. ${ }^{*} \mathrm{P}<0.10$, $+\mathrm{P}<.05$, $\neq \mathrm{P}<.01, \S \mathrm{P}<.001, \||| \mathrm{P}<0.0001$.

such as pneumonia, sepsis, neonatal respiratory distress syndrome and congenital heart disease. Quality care with less expense could be strengthened through nurse training on the recognition of danger vitals and instituting algorithms under the focus of essential emergency and critical care. 1,3,36 Additionally, public health education efforts to these remote provinces could aid the early recognition of child illness by their caretakers and improve health outcomes. ${ }^{37}$

\section{LIMITATIONS}

In our sample, we were unable to assess cases from different geographic distances that required the resources of $\mathrm{VNCH}$, but could not come to VNCH either from an income standpoint or from a medical standpoint. These patients represent key demographic populations at risk and their omission introduces bias into our analysis; however, their data retrieval would be incredibly complex from multiple primary and secondary care centers. We also did not survey patients who were at risk of imminent mortality upon admission, and may represent an important population to analyze socio-demographic differences, for ethical reasons. We may also require more outcome data to determine precise ORs for the risk factors of $>1$ days delayed to care/ $\mathrm{VNCH}$ and $>1$ patient referrals because in these specific cases we only had 2-3 patients discharged. Thus, the calculated ORs and 95\% CLs are large albeit significant.

An additional limitation is that we did not ascertain the valence of factors that impacted caregiver's decision to seek care (positively/negatively impacted the decision) and can only hypothesize that insurance was a positive influence to seek care whereas further distances to care or to VNCH was a negative influence. Medical records, while electronic in the ED, were paper-form in the ICU - which complicated the recording and contributed to loss of follow-up of patient outcomes. Lastly, given the northern location and time frame, results of our study may not extend to all of Vietnam.

\section{CONCLUSIONS}

Our data indicate a clear need to improve and better mobilize resources for those disproportionately affected children and their caretakers who live long distances from tertiary care centers and are therefore at-risk of worse health outcomes and delayed care-seeking behavior. 
A. Impact Decision to Seek Care?

N OR $(95 \% \mathrm{CL})$

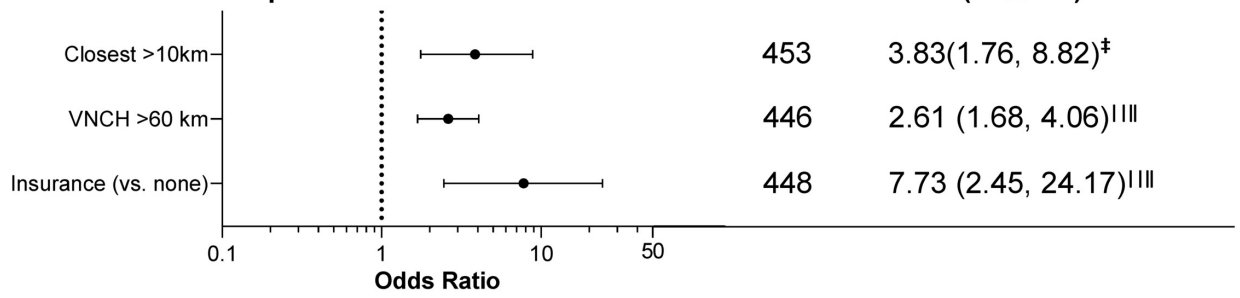

B.

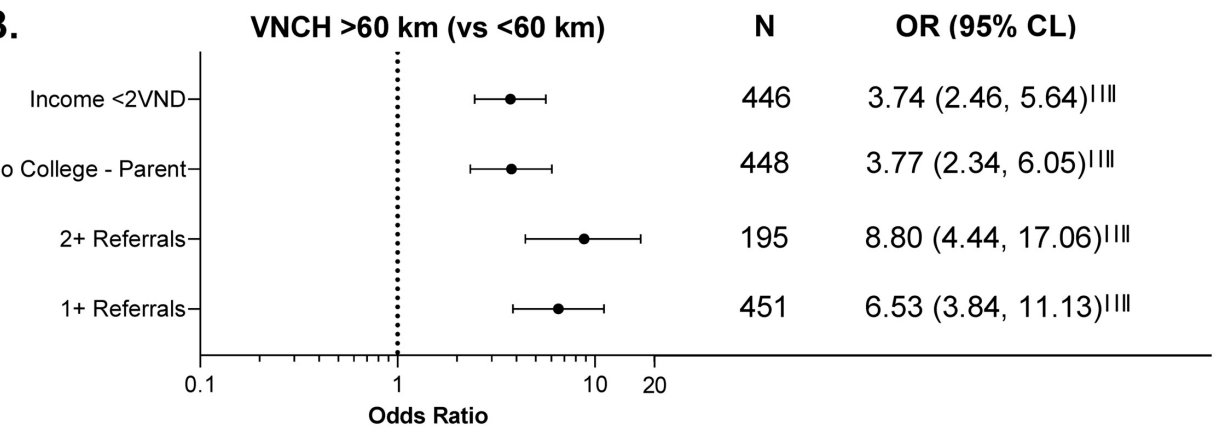

Figure 5. Odds ratios for care-seeking behavior $\mathrm{N}=$ number of patients, $\mathrm{OR}=$ odds ratio, $95 \% \mathrm{CL}=95 \%$ confidence limit.

*P $<0.10,+\mathrm{P}<.05, \neq \mathrm{P}<.01, \S \mathrm{P}<.001, \| \mathrm{P}<0.0001$

A.

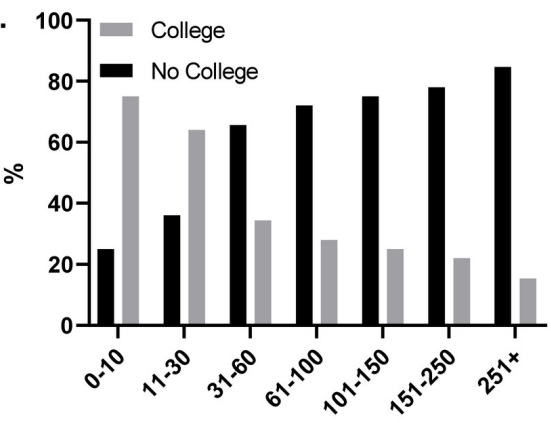

Distance to VNCH $(\mathbf{k m})$

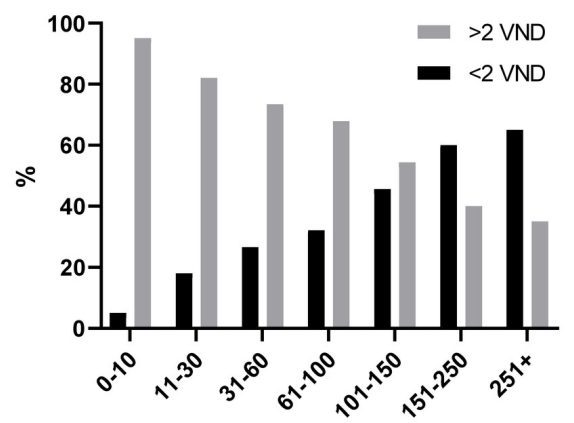

Distance to VNCH (km)

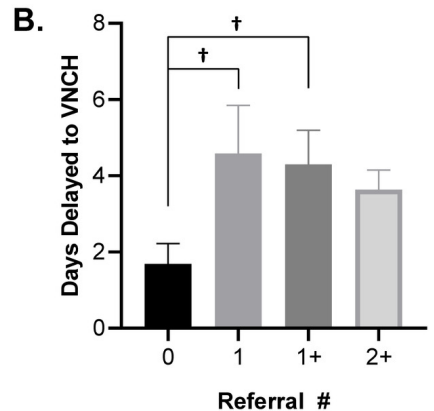

Referral \#

Figure 6. Care-seeking determinants and their inter-relationships.

Panel A. Patients and their caretakers were divided into groups based on distances to VNCH and the percentages per group plotted for college/no college education and income over/under 2 million VND per family member. Panel B. Mean days delayed to VNCH was graphed based on the number of referrals the patient experienced. * $\mathrm{P}<0.10$, $+\mathrm{P}<.05, \neq \mathrm{P}<.01, \S \mathrm{P}<.001,\|\| \mathrm{P}<0.0001$.

Acknowledgements: We would like to thank Vietnam National Children's Hospital for their excellence in making this study possible. We thank Dyda Dao for critical insights regarding statistical testing. We declare no competing interests.

Ethics Approval: This study received ethics approval at both Mayo Clinic in Rochester, Minnesota and Vietnam National Children’s Hospital.

Funding: There was no direct funding for this research.
Authorship Contributions: DR, TX and YO conceived and oversaw all components of the project. DR, TX, VH, KT, $\mathrm{TP}$, and DL generated the survey components and data retrieval. DR, TX, SK performed data entry and data analysis. $\mathrm{DR}, \mathrm{TX}$, and YO wrote the paper.

Competing Interests: The authors completed the Unified Competing Interest form at www.icmje.org/coi disclosure.pdf (available upon request from the corresponding author), and declare no conflicts of interest. 


\section{Correspondence to:}

Yves Ouellette, MD-PhD

Consultant, Mayo Clinic

Department of Pediatric and Adolescent Medicine

Division of Pediatric Critical Care Medicine

$2001^{\text {st }}$ St SW

Rochester, MN55905

USA
Ouellette.yves@mayo.edu

David A Rollins, PhD

Mayo Clinic

Alix School of Medicine M3

$2001^{\text {st }}$ St SW

Rochester, MN55905

USA

rollins.david@mayo.edu

This is an open-access article distributed under the terms of the Creative Commons Attribution 4.0 International License (CCBY-4.0). View this license's legal deed at http://creativecommons.org/licenses/by/4.0 and legal code at http://creativecommons.org/licenses/by/4.0/legalcode for more information. 


\section{REFERENCES}

1. Schell CO, Gerdin Wärnberg M, Hvarfner A, et al. The global need for essential emergency and critical care. Crit Care. 2018;22(1). doi:10.1186/s13054-018-2 219-2

2. Firth P, Ttendo S. Intensive Care in Low-Income Countries - A Critical Need. N Engl J Med. 2012;367(21):1974-1976. doi:10.1056/nejmp1204957

3. Murthy S, Adhikari NK. Global health care of the critically ill in low-resource settings. Annals ATS. 2013;10(5):509-513. doi:10.1513/annalsats.201307-24 $\underline{60 t}$

4. Baker T. Critical care in low-income countries. Tropical Medicine \& International Health. 2009;14(2):143-148. doi:10.1111/j.1365-3156.2008.02 202.X

5. Slusher TM, Kiragu AW, Day LT, et al. Pediatric Critical Care in Resource-Limited Settings-Overview and Lessons Learned. Front Pediatr. 2018;6. doi:10.33 89/fped.2018.00049

6. Vukoja M, Riviello ED, Schultz MJ. Critical care outcomes in resource-limited settings. Current Opinion in Critical Care. 2018;24(5):421-427. doi:10.1 097/mcc.0000000000000528

7. Treleaven E, Pham TN, Le DN, Brooks TN, Le HT, Partridge JC. Referral patterns, delays, and equity in access to advanced paediatric emergency care in Vietnam. Int J Equity Health. 2017;16(1). doi:10.1186/ $\underline{\text { s12939-017-0703-y }}$

8. Diaz JV, Riviello ED, Papali A, Adhikari NKJ, Ferreira JC. Global critical care: Moving Forward in resource-limited settings. Annals of Global Health. 2019;85(1). doi:10.5334/aogh.2413

9. O’Connell TS, Bedford KJA, Thiede M, McIntyre D. Synthesizing qualitative and quantitative evidence on non-financial access barriers: Implications for assessment at the district level. Int J Equity Health. 2015;14(1). doi:10.1186/s12939-015-0181-z

10. Nesbitt RC, Lohela TJ, Soremekun S, et al. The influence of distance and quality of care on place of delivery in rural Ghana. Sci Rep. 2016;6(1). doi:10.103 8/srep30291

11. Nicholl J, West J, Goodacre S, Turner J. The relationship between distance to hospital and patient mortality in emergencies: An observational study. Emergency Medicine Journal. 2007;24(9):665-668. do i:10.1136/emj.2007.047654
12. Lake IR, Jones NR, Bradshaw L, Abubakar I. Effects of distance to treatment centre and case load upon tuberculosis treatment completion. European Respiratory Journal. 2011;38(5):1223-1225. doi:10.11 $\underline{83 / 09031936.00036211}$

13. Ferkol T, Schraufnagel D. The global burden of respiratory disease. Annals ATS. 2014;11(3):404-406. doi:10.1513/annalsats.201311-405ps

14. Turner HC, Hao NV, Yacoub S, et al. Achieving affordable critical care in low-income and middleincome countries. BMJ Glob Health. 2019;4(3):e001675. doi:10.1136/bmigh-2019-001675

15. Nguyen C. The impact of health insurance programs for children: Evidence from Vietnam. Health Econ Rev. 2016;6(1). doi:10.1186/s13561-01 6-0111-9

16. Nga L. Phụ huynh chưa tin tưởng vào Bảo hiểm y tế học sinh. Newspaper Vnexpress.

17. Vietnam. Development Report 2004 - Poverty (English). Washington, DC: World Bank; 2003.

18. Palmer M, Mitra S, Mont D, Groce N. The impact of health insurance for children under age 6 in Vietnam: A regression discontinuity approach. Social Science \& Medicine. 2015;145:217-226. doi:10.1016/ j.socscimed.2014.08.012

19. Cheng T-M. Vietnam's health care system emphasizes prevention and pursues universal coverage. Health Affairs. 2014;33(11):2057-2063. do i:10.1377/hlthaff.2014.1141

20. Nguyen H, Wang W. The effects of free government health insurance among small childrenevidence from the free care for children under six policy in Vietnam. Int J Health Plann Mgmt. 2013;28(1):3-15. doi:10.1002/hpm.2114

21. Kempen JH, Pistilli M, Begum H, et al. Remission Of Non-Infectious Anterior Scleritis: Incidence And Predictive Factors. American Journal of Ophthalmology. April 2019. doi:10.1016/j.ajo.2019.0 $\underline{3.024}$

22. Thoa NTM, Thanh N, Chuc NTK, Lindholm L. The impact of economic growth on health care utilization: A longitudinal study in rural Vietnam. International Journal for Equity in Health. 2013;12(1):19. doi:10.11 86/1475-9276-12-19 
23. Van Minh H, Oh J, Hoat LN, Lee J-K, Williams JS. Millennium Development Goals in Vietnam: Taking Multi-sectoral Action to Improve Health and Address the Social Determinants. Global Health Action. 2016;9(1):31271. doi:10.3402/gha.v9.31271

24. Jowett M, Contoyannis P, Vinh ND. The impact of public voluntary health insurance on private health expenditures in Vietnam. Social Science \& Medicine. 2003;56(2):333-342. doi:10.1016/s0277-9536(02)0003 $\underline{1-\mathrm{X}}$

25. Wagstaff A, Pradhan M. Insurance Health Impacts on Health and Non-Medical Consumption in a Developing Country. The World Bank; 2005. doi:10.15 96/1813-9450-3563

26. Green NA, Durani Y, Brecher D, DePiero A, Loiselle J, Attia M. Emergency Severity Index version 4: A valid and reliable tool in pediatric emergency department triage. Pediatric Emergency Care. 2012;28(8):753-757. doi:10.1097/pec.0b013e31826218 13

27. Jafari-Rouhi AH, Sardashti S, Taghizadieh A, Soleimanpour H, Barzegar M. The Emergency Severity Index, version 4, for pediatric triage: A reliability study in Tabriz Children's Hospital, Tabriz, Iran. Int J Emerg Med. 2013;6(1). doi:10.1186/1865-1380-6-36

28. Shrestha GS, Goffi A, Aryal D. Delivering neurocritical care in resource-challenged environments. Curr Opin Crit Care. 2016;22:100-115. doi:10.1097/MCC.0000000000000285

29. Inglis R, Ayebale E, Schultz MJ. Optimizing respiratory management in resource-limited settings. Current Opinion in Critical Care. 2019;25(1):45-53. $\underline{\mathrm{d}}$ oi:10.1097/mcc.0000000000000568
30. Kang SJ, Lee TW, Paasche-Orlow MK, Kim GS, Won HK. Development and evaluation of the Korean Health Literacy Instrument. Journal of Health Communication. 2014;19(sup2):254-266. doi:10.108 0/10810730.2014.946113

31. Geldsetzer P, Williams TC, Kirolos A, et al. The recognition of and care seeking behaviour for childhood illness in developing countries: A systematic review. Semple MG, ed. PLoS ONE. 2014;9(4):e93427. doi:10.1371/journal.pone.0093427

32. Cohen AK, Syme SL. Education: A missed opportunity for public health intervention. Am J Public Health. 2013;103(6):997-1001. doi:10.2105/ajp $\underline{\text { h.2012.300993 }}$

33. Chou S-Y, Liu J-T, Grossman M, Joyce T. Parental Education and Child Health: Evidence from a Natural Experiment in Taiwan. American Economic Journal: Applied Economics. 2010;2(1):33-61. doi:10.1257/ap p.2.1.33

34. Prickett KC, Augustine JM. Maternal Education and Investments in Children's Health. Fam Relat. 2016;78(1):7-25. doi:10.1111/jomf.12253

35. Karra M, Fink G, Canning D. Facility distance and child mortality: A multi-country study of health facility access, service utilization, and child health outcomes. Int J Epidemiol. May 2016:dyw062. doi:1 $\underline{0.1093 / \mathrm{ije} / \mathrm{dyw} 062}$

36. Schell CO, Castegren M, Lugazia E, et al. Severely deranged vital signs as triggers for acute treatment modifications on an intensive care unit in a lowincome country. BMC Res Notes. 2015;8(1). doi:10.11 86/s13104-015-1275-9

37. Hahn RA, Truman BI. Education Improves Public Health and Promotes Health Equity. Int J Health Serv. 2015;45(4):657-678. doi:10.1177/0020731415585986 


\section{SUPPLEMENTARY MATERIALS}

\section{Online Supplementary Document}

Download: https://www.joghr.org/article/12102-distance-travelled-to-tertiary-pediatric-care-impacts-care-seekingbehavior-and-hospital-outcome-in-vietnam/attachment/30662.pdf 